the same price as the non-opaque variety.We are, etc.,

EDWARD BOWMAN.

London N.W.8. RodNey GRahame.

\section{Myeloma and Neuropathy}

SIR,-Dr. D. I. Rushton's report of a case of peripheral sensorimotor neuropathy in association with a localized myeloma ( $24 \mathrm{July}$, p. 203) is of particular interest since it is the sixth in which the myeloma has been sclerotic, a relatively high incidence of osteosclerosis since Aguayo et al. ${ }^{1}$ were only able to find 20 cases of osteosclerosis myeloma in the literature. The first case was Victor et al.' case. ${ }^{12}$ The second and third cases were reported by Odelberg-Johnson ${ }^{3}$ and Aguayo et al..$^{1}$ Brain told Aguayo et al. ${ }^{1}$ of a fourth. Admittedly Rushton's case showed only " an area of sclerosis," but cases of sclerotic myeloma with neuropathy should be carefully noted until it is clear whether sclerosis is really more frequent in patients with neuropathy. In our own case, ${ }^{4}$ as in that of Rushton, the myeloma was solitary and in a vertebra, but was densely isclerotic. It was published in the local medical journal as a clinicopathological report. It is ironic that it escaped the attention of workers only four miles away.-I am, etc.,

\section{Midland Centre for Neursurgery}

$$
\text { A. L. WOOLF. }
$$

\title{
REFERENCES
}

1 Aguayo, A., Thompson, D. W., and Humphrey, J. G., f. Neurol. Neurosurg. Psychiat., 1964, 2 Victor, M., Banker, B. Q., and Adams, R. D. ibid., 1958, 21, 73 .

3 Odelberg-Johnson, O., Acta radiol. (Stockh.), $1959,52,139$.

Small, J. M., Moxon, C. P., and Woolf, A. L. Bgham med. Rev., 1961, 20, 546.

\section{C.S.F.-protein Fractions}

SIR,-The value of a knowledge of the total cerebrospinal-fluid (C.S.F.) protein in neurological disease is well recognized. It is less easy to determine the protein fractions in cerebrospinal fluid. However, in this laboratory a method has been evolved making use of the Chromoscan as a transmission instrument. The method is relatively simple and may be of interest in other laboratories.

The total C.S.F. protein is first demonstrated by a turbidimetric method and at the same time the red-cell and white-cell count. One millilitre of C.S.F. is then taken and dialysed against $40 \%$ sucrose in physiologically normal saline using Viskin $32 / 32^{\prime \prime}$ tubing at room temperature until the volume has reduced to almost zero, or, if the protein concentration of the original is over $150 \mathrm{mg}$., until $0.1 \mathrm{ml}$. of the C.S.F. remains. The protein in the sac is taken up in $0.1 \mathrm{ml}$. of saline if the volume has been reduced to zero. The saline is added through a hole in the top of the dialysis sac and left in contact with the protein in the sac for two hours in the cold. Periodically the sac is removed from the fridge and the protein-saline solution in the sac rolled between the fingers, so that all protein on the wall will have the chance of dissolving. If no saline is added the sac is still left in the cold for two hours with periodic rolling to ensure solution of the protein.

At the end of two hours $0.01-\mathrm{ml}$. aliquots of protein solution may be withdrawn from the sac and applied in a line to a cellulose acetate strip

which has been soaked in barbitone buffer $p H$ 8.6. The point of application should be halfway along the $10 \times 2.5 \mathrm{~cm}$. strip, and several strips are prepared. The strips are electrophoresed in a Shandon Tank, using $1 \mathrm{ma}$. per strip, and separation is effected in less than an hour. After blotting the strips dry they are stained in Ponceau Red and the excess dye removed with $5 \%$ acetic acid. The strips are then allowed to dry between folds of filter paper, pressed flat with a weight.

It has been found possible to appreciate visually some of the protein bands from C.S.F. of protein content $50-60 \mathrm{mg} . / 100 \mathrm{ml}$. in the original. The strips may be scanned using the Chromoscan as a transmission instrument.

The procedure has been checked by diluting normal serum to a concentration of $60 \mathrm{mg}$./ $100 \mathrm{ml}$., reconcentrating, and comparing the scans before and after. It has been found possible to identify pre-albumin, albumin, $\alpha_{1}, \alpha_{2}, \beta$, and $\gamma$ globulin peaks by this method. By careful preparation of the electrophoretic strip it is possible to obtain results from successive strips which differ by no more than $2 \%$ for the albumin and globulin fractions. Cerebrospinal fluids with initial protein concentrations of $40-500 \mathrm{mg} . / 100$ ml. have been successfully treated in this way.

The method of protein analysis is now being applied to clinical cases and will be evaluated in relation to the specific cases later.-I am, etc.,

\section{Derbyshire Royal Infirmary,}

WILLIAM H. S. GeORGe.

Derby.

\section{Antidepressant Drugs for Enuresis}

SIR,-In his article on incontinence of urine (10 July, p. 91) Dr. Douglas Gairdner does not mention the use of the new antidepressant drugs in the treatment of enuresis. There are few cases of so-called functional enuresis which will not respond to amitriptyline $(20 \mathrm{mg}$. at night for an 8-year-old, with another $10 \mathrm{mg}$. in the morning in resistant cases). Imipramine in divided doses through the day has also given good results. Enuretic children often become dry within a week of starting treatment.

I cannot remember seeing a child with functional enuresis who did not have at least one parent with a depressive diathesis, and it might very well be that enuresis is part of a genetically determined depressive illness. It is possible that monoamine oxidase inhibitors could be equally effective, but one would hesitate to use them in view of the difficulty in controlling a child's diet.-I am, etc.,

$$
\begin{array}{ll}
\text { East Looe, } \\
\text { Cornwall. }
\end{array}
$$

\section{Indomethacin Suppositories for Arthritis}

SIR,-With regard to the article by Dr. L. P. J. Holt and Dr. C. F. Hawkins (22 May, p. 1354), we have recently used indomethacin suppositories in 11 patients. Nine of these had gastric intolerance to anti-inflammatory drugs by mouth, gastric ulcers being demonstrated by barium meal in two cases. A dose of $100 \mathrm{mg}$. at noon and $100 \mathrm{mg}$. at night was found to be -most effective. In all cases proctoscopy showed normal rectal mucosa, a finding noted by the authors.

Seven of our patients had rheumatoid arthritis, and five of these made a good response without side-effects. One of this group complained of giddiness, which was relieved by halving the dose given in suppository form while maintaining the same amount of symptomatic relief. In one case where no improvement was made on indomethacin by mouth therapeutic response was obtained by the suppository form. In two further cases of rheumatoid arthritis indomethacin capsules were given in a dose of $25 \mathrm{mg}$., three times a day, together with a $100-\mathrm{mg}$. suppository at night. Considerable relief of morning stiffness occurred.

Two cases of acute gout with severe dyspepsia obtained relief within 48 hours while on indomethacin suppositories-in one case twice daily and in the other three a day -without side-effects.

We endorse the findings of Dr. Holt and Dr. Hawkins that indomethacin suppositories are of use in gaining relief from arthritis where capsules are contraindicated, or to supplement total daily dosage. It is particularly useful when morning stiffness is the dominant symptom.-We are, etc.,

\section{London S.W.1. F. DUDLEY HART.}

\section{Plasma-renin Concentration in Hypertension}

SIR,-In their recent paper Dr. J. J. Brown and his colleagues (17 July, p. 144) have pointed out the inverse relationship between plasma-resin concentration and serum sodium. Observations in this laboratory have demonstrated a similar inverse relationship between plasma renin and diastolic blood-pressure in normotensive subjects. It is well known that patients with essential hypertension have usually a rather low plasma-renin concentration, while among patients with renal artery stenosis some have a high plasma-renin concentration. It is also known that the kidney responds to a fall in blood-pressure by increased output of renin, and it is suggested, therefore, that the usefulness of a plasmarenin reading is increased if account is taken of the blood-pressure at the time the specimen is taken.

Measurement of plasma renin may distinguish a normal kidney from one which is maintaining a plasma-renin level inappropriate to the systemic blood-pressure, as may occur in renal artery stenosis. The total range of plasma-renin concentration in normal subjects is wide: reference to the blood-pressure narrows the range, and reference to the plasma sodium narrows it further. It is suggested that use of i a nomogram relating serum sodium, diastolic bloodpressure, and plasma renin may help more accurately to distinguish appropriate from inappropriate renin secretion.-I am, etc.,

$$
\text { Cardiff Royal Infirmary, P. T. PICKens. }
$$
Cardiff, Glamorgan.

\section{Anaphylactoid Shock Due to Penicillin}

SIR,-Dr. A. M. Fox's account of Gerstmann's syndrome resulting from anaphylactoid shock induced by oral penicillin in to-day's B.M.F. (24 July, p. 206) is most interesting, but I beg to dispute his opening statement, as I reported an anaphylactoid 
reaction to oral phenoxymethylpenicillin in 1957.'

Regarding treatment of any anaphylactoid reaction, I am sure prompt recognition is vital, and I am equally sure that prompt administration of adrenaline is the correct initial course because it is effective, acts quickly, and every doctor carries it in his bag.-I am, etc.,

Leeds 17.

M. Dales.

REFERENCE

1 Dales, M., Brit. med. F., 1957, 2, 1366.

SIR,-I was interested in the clinical report by Dr. A. M. Fox (24 July, p. 206) which closely resembles, in its general and neurological aspects, a case of encephalopathy following a sting which I have described in detail elsewhere. ${ }^{1}$ The cerebral disorder found in some other cases of sting appears to have a vascular basis. Cerebral oedema and infarction, sometimes haemorrhagic infarction, are well documented. ${ }^{2}$

While it is well known that penicillin introduced into the cerebral ventricles or spinal theca in high concentration may have severe neurological effects it seems unnecessary to postulate that the penicillin given (orally) had any direct effect on the brain. I would agree with Dr. Fox that these unusual neurological manifestations are most likely to be secondary to anaphylactic shock with hypotension.-I am, etc.,

Royal Infirmary, Bristol.
BryAN AshwORTH.

REFERENCES

1 Ashworth, B., f. Neurol. Neurosurg. Psychiat.,

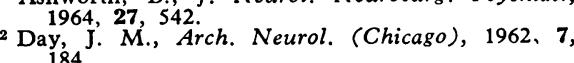

\section{Diagnosis of Hysteria}

SIR,-Dr. E. Slater's stimulating paper on "Diagnosis of "Hysteria ", (29 May, p. 1395) raises a number of questions. He appears to regard "hysteria" as a form of normal behaviour. ". . . All the signs of "hysteria" are the signs not of disease but of health." And again ". . . If it is shown that one out of a group of symptoms is 'hysterical,' this is merely to demonstrate that in respect of this symptom the patient is showing a normal and not a pathological reaction." A similar view is taken by Szasz. ${ }^{1}$ We believe that all so-called neurotic behaviour is normal and not pathological.

Dr. Slater uses the headings "Frequency of Misdiagnosis," and "Basic Organic Disabilities" and ends by saying: "The diagnosis of 'hysteria' is a disguise for ignorance and a fertile source of clinical error. It is in fact not only a delusion but also a snare."

We suggest that one can overcome the difficulties by recognizing hysteria (and other "neurotic" behaviour) as adaptive responses. The content of these responses is the assumption of one or more of the attributes of the role of sick person. The forms which these take are all varieties of hysterical (and "neurotic") behaviour.

There are many reasons for people choosing such forms of adaptation. To be accepted as sick confers many privileges; enables one to avoid responsibilities; and entitles one to receive help, or attention, or sympathy, sometimes all three. Some solve interpersonal difficulties and learn to control and manipulate others. Some wish to receive euphoriant drugs. Some are persuaded by the medical profession that their complaints are evidence of illness and they are treated accordingly. As Dr. Slater indicates, there are others whose efficiency is impaired so that their adaptive responses are limited, and may include "hysterical behaviour." Such will occur in those with physical disease, especially disease of the nervous system.

If hysteria is regarded as adaptive behaviour it need not be regarded as mental illness, and many other contradictions are resolved. While adaptive behaviour may be more or less successful, it cannot be judged by its outcome.

It is as wrong to treat "hysteria" as a disease because some people exhibiting such behaviour develop physical illness as it is to treat the physically ill as not sick because they exhibit "hysteria."-We are, etc.,

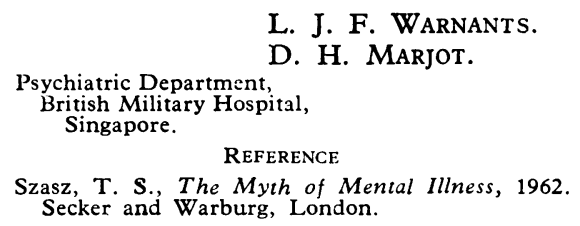

\section{Thumb-sucking and the Teeth}

SIR,-As a dental practitioner I grow increasingly weary of the statement, repeated by Dr. John Apley in his paper on behavioural disorders (17 July, p. 157), that sucking the thumb has little effect on the teeth. I have to cope with this problem daily, and my advice is frequently ignored or even derided because the patient's doctor has said that thumb-sucking is harmless, or enforced withdrawal may produce other and worse symptoms.

If a child sucks thumb or fingers and holds the digits in a perfectly horizontal position whilst sucking, the only damage that ensues is the delayed eruption of the permanent teeth, which drop into position as soon as the habit stops. If the child sucks the thumb holding it in the vertical position with the full weight of the hand resting on the lower jaw, then by the age of 3 irretrievable damage has occurred, and by the age of 6 nothing short of plastic surgery can remedy the resultan small lower jaw and vastly extended premaxilla. And I can assure Dr. Apley that the psychological harm such a deformity produces in a teen-age girl is great.

Sucking the thumb is most pronounced just at the time the child is going to sleep, and I have discovered that if the habit can be stopped at this moment then it rapidly drops off at other times. I advise parents to seek the co-operation of the child if old enough, but in any case to carefully bind socks on both hands just before going to bed so that it is impossible to suck anything but a woolly sock. This should be continued for about six weeks. The first few nights might be restless, and I usually prescribe a mild sedative for this. In the case of small children there is usually some squalling protest, which should be ignored.

With this method many children in this area have been cured of this dentally perni- cious habit. To date I have had no report of any other behavioural disorder arising as a result of the treatment, and in children of older age groups most of them seem to be extremely grateful to be rid of a habit which they wanted to stop but could not do unaided.

In the circumstances I have described, thumb-sucking in infancy produces a gross and lifelong deformity of the dentition and jaws which is not amenable to ordinary orthodontic methods, and is perhaps the most intractable orthodontic problem facing the dental practitioner to-day. As most patients have far more respect for the advice given to them by their doctors than by their dentists, it is to be hoped that the medical profession will exercise the greatest caution in its future advice regarding the problem of thumbsucking.-I am, etc.,

Norwich, Norfolk.

C. A. Pitt-Steele.

\section{New Museum Dedicated to Semmelweis}

SIR,-The centenary of the death of Ignace Semmelweis falls on 13 August of this year. To mark the occasion the Hungarian Ministry of Health has had the house where Semmelweis was born restored, and has established a museum in it. On 15 October 1964 the mortal remains of Semmelweis were transported hither from the cemetery and placed into the tomb situated at the far end of the house at the foot of Castle Hill at Várhegy. In front of the tomb stands the statue "Motherhood," the work of the renowned Hungarian sculptor and Kossuth Prize laureate, Miklós Borsos.

The house were Semmelweis was born stands in Buda (Apród utca 1-3), at the foot of Castle Hill. The successful general-store run by Semmelweis's father was also situated there.

The house was built at the beginning of the 18 th century in the style of Louis XVI, and it is decorated with lovely garlands on its façade. With its 13 windows giving on the street, it was rather spacious according to middle-class standards of that time. Some time ago it was declared a historic building and in 1906, when a statue of Semmelweis was unveiled, a commemorative plaque was affixed to the wall. In the second world war the house was hit by a bomb and partly destroyed. Nevertheless, thanks to clever restoration nothing of its beauty has been lost and all the details have been preserved. The glass panes of the wide doorway make it possible to see Semmelweis's tomb and his statue even from the street.

The museum houses a collection of medical and pharmaceutical relics. One of the rooms is dedicated to the memory of Ignace Semmelweis ; it contains a few pieces of his furniture-a writing-table, some book-cases, and small dressing-tables-and on the walls there are portraits of his parents as well as of Semmelweis himself and of his wife, painted by the artist A. Canzi in 1857.

Only a few keepsakes of Semmelweis have been preserved-a few letters and some shor poems written in his childhood on the occasion of family gatherings. All these prove the happy domestic life of the family and the sound education given to the children. Semmelweis's small jewel-case has also been kept, though as it is little larger than a matchbox it could not have contained many valuables.

In the Semmelweis room there are also number of writings about him-books (including the excellent biography written by Sir William Sinclair) and some periodicals. The other 